\title{
Damage Evolution and Circumferential Strain Distribution Characteristics of the Bolt-Supported Cavern under Multiple Explosion Sources
}

\author{
Taotao Wang, ${ }^{1}$ Ansheng Cao $\mathbb{D}^{\circ},{ }^{2}$ Weiliang Gao, ${ }^{1}$ Guangyong Wang $\mathbb{D}^{1,}, 2$ and Xiaowang Sun ${ }^{3}$ \\ ${ }^{1}$ Huanghe Jiaotong University, Jiaozuo 454950, China \\ ${ }^{2}$ School of Civil Engineering, Henan Polytechnic University, Jiaozuo 454000, China \\ ${ }^{3}$ School of Mechanical Engineering, Nanjing University of Science and Technology, Nanjing 210094, China
}

Correspondence should be addressed to Guangyong Wang; wgy2003@mail.ustc.edu.cn

Received 30 March 2021; Accepted 11 June 2021; Published 21 June 2021

Academic Editor: Jianwei Cheng

Copyright ( 2021 Taotao Wang et al. This is an open access article distributed under the Creative Commons Attribution License, which permits unrestricted use, distribution, and reproduction in any medium, provided the original work is properly cited.

The impact of multiple explosion sources on the safety of the underground cavern is enormous. Based on a similarity model test, the finite element software LS-DYNA3D was utilized to analyze the damage evolution and circumferential strain distribution characteristics of the bolt-supported cavern under the seven combinations of concentrated charge explosion sources in three places, including the side of the vault, side arch, and sidewall. The accuracy of the simulation results is verified by comparing them with test results. The research results indicate that the damage of the surrounding rock is mainly caused by the tensile stress wave reflected from the free surfaces and the superposition of the tensile stress wave. The damage of the surrounding rock in the cases of multiple explosion sources is not a simple superposition of that in the cases of a single explosion source. The peak circumferential stress and damage of the surrounding rock in the middle of two explosion sources are significantly greater than that of the cases of the corresponding single explosion source. In the seven cases, the peak circumferential strain of the cavern wall changes from tensile to compressive from the vault to the spandrel. When the explosion occurs on the sidewall, the peak circumferential strain of the floor is tensile.

\section{Introduction}

Underground engineering has been widely used in civil and military fields in recent years because of its advantages such as large storage space, little impact on the environment, and good concealment. However, underground engineerings are vulnerable to explosions, such as blasting excavation and demolition, terrorist attacks by bombs, and there are usually multiple explosion sources when such explosions occur. The surrounding rock is disturbed during the explosion, and the stability of the underground cavern is significantly reduced [1]. Therefore, it is of great practical significance to study the damage and strain distribution characteristics of underground caverns under multiple explosion sources.

The explosion may occur inside or outside the underground cavern. During the construction period, underground projects are prone to internal explosions, but in the operation period, due to strict inspection and monitoring, the possibility of internal explosions in underground projects is very small. Many scholars have studied the effects of internal explosions on underground caverns. Zhu et al. [2] studied the influence of internal explosions with different charge densities on the dynamic response and stress wave propagation of the surrounding rock caused by the explosion in the tunnel, and found that the charge density has a great influence on the dynamic response of the surrounding rock in an uncoupled underground explosion. Employing test and numerical methods, many scholars [3-6] have studied the dynamic response of the cavern under the internal gas explosion. On the other hand, the explosion outside the cavern cannot be predicted in advance, which is more likely to happen and cause greater damage to the 
cavern. In this research field, due to the large demand for explosives, high test risk, and high cost, there are few records of the field test. The U.S. Army Corps of Engineers conducted a large-scale explosion test in sandstone to study the damage of unlined tunnels, and Hendron [7] derived the classic peak particle velocity (PPV) damage criterion for tunnels based on this. In seven coal mines, Singh [8] studied the influence of large-scale blasting in open-pit coal mines on the stability of underground working faces in adjacent coal mines, and proposed the vibration threshold to ensure the safety of underground working faces. Through field tests, Xia et al. [9] studied the influence of blasting excavation on the surrounding rock and lining system of the adjacent existing tunnel, and found that the damage degree of the surrounding rock increases linearly with the PPV. Xu et al. [10] studied the dynamic response of deep rock mass under blasting load on-site and found that deep rock mass is more vulnerable to damage than shallow rock mass under blast load. Rajmeny et al. [11] studied the phenomenon of spalling and collapse of the surrounding rock of cavern through the field blasting test.

The reduced centrifugal model technology can use fewer explosives to simulate large-scale explosions under high gravitational acceleration $[12,13]$. De et al. $[14,15]$ used geotechnical centrifuges to study the influence of surface explosion on underground tunnels through physical models. The similarity model test can be optimized in the early stage, and has the characteristics of saving time and energy. Using the geotechnical engineering anti-blast structure model [16], Gu et al. [17-20] studied the antiblast performance of underground caverns with different charging and anchoring methods through similarity model tests.

In recent years, with the enhancement of computer computing power, numerical simulation has been widely used in this field. Using finite element software ABAQUS, Chang et al. [21] studied the failure mode of the cement mortar cavern reinforced with aluminum bars under top explosion. Mussa et al. [22] studied the damage behavior of the underground box tunnel caused by a vehicle bomb by using ANSYS/LS-DYNA. Through discrete element software UDEC, many scholars [23-25] studied the propagation of stress waves generated by the explosion in the jointed rock mass and found that the buried depth of underground cavern and joint properties including stiffness, spacing, and dip angle have significant effects on the propagation of stress waves. Deng et al. [26] used UDEC to simulate the damage of an existing circular tunnel under an external explosion, and analyzed the damage of the tunnel through the PPV of the tunnel surface. It was found that the bolt can improve the stability of the tunnel by changing the vibration form of particle velocity instead of reducing the PPV. Many scholars [27-29] used numerical simulation methods to analyze the damage of underground caverns under the explosions by analyzing the PPV, displacement, and acceleration of the surrounding rock.

The research on the influence of external explosions on the cavern has been very comprehensive. Unfortunately, such research excessively focuses on the single explosion source, and the case of multiple explosion sources is very rare. However, the case of multiple explosion sources is more common in practice. Therefore, based on a similarity model test, the finite-element software LS-DYNA is used to build an underground cavern model that encounters multiple explosion sources. The research results can provide references for the anti-explosion design of underground caverns.

\section{Overview of the Test Model}

The numerical calculation model is taken from the similarity test model, and the test device has been recorded by Wang et al. [30], so only a brief overview is given here. The model test simulates the situation where a cavern with a buried depth of $15 \mathrm{~m}$ and a span of $7 \mathrm{~m}$ encounters an explosion above the vault. The density, length, and stress similarity coefficient are determined to be $K_{\rho}=0.67, K_{l}=0.09$, and $K_{\sigma}=0.06$ according to the Froude scale method. After similarity conversion, the width, height, and thickness of the model are $2.4 \mathrm{~m}, 2.3 \mathrm{~m}$, and $1.5 \mathrm{~m}$, respectively, and the span of the cavern is $0.6 \mathrm{~m}$. The cavern is reinforced by a single row of full-length bonded rock bolts with spacing and row spacing of $4 \mathrm{~cm}$ and a length of $24 \mathrm{~cm}$. The surrounding rock is considered as class III rock mass, and the proportion of sand, cement, water, and accelerator is $15: 1: 1.6: 0.0166$. The cavern model is fixed by four rigid lateral limiting devices that can move forward and backward. To eliminate the reflection of the stress wave on the side, aluminum wave elimination plates with a hole ratio of up to $50 \%$ are set on the anti-explosion surface of each device. The rock bolts are simulated by aluminum rods. In the model test, a $100 \mathrm{~g}$ TNT explosion occurs at $0.83 \mathrm{~m}$ above the vault of the cavern, as shown in Figure 1.

\section{Numerical Model}

3.1. Finite Element Model. To improve the calculation efficiency, considering the symmetry of the test model, the numerical calculation simplified it to a geometric model with a length of $2.4 \mathrm{~m}$, a width of $0.4 \mathrm{~m}$, a height of $2.3 \mathrm{~m}$, and a span of $0.6 \mathrm{~m}$. According to the distance from the explosion source to the vault in the test model, TNT explosion sources, each with a mass of $50 \mathrm{~g}$, are positioned at the side of the vault, side arch, and sidewall in the numerical calculation model, i.e., top explosion, side arch explosion, and sidewall explosion, as shown in Figure 2. The seven calculation cases include a single explosion source, double explosion sources, and three explosion sources, as shown in Table 1.

3.2. Material Model and Parameters. The left, right, and lower boundaries of the model are set as nonreflective boundary conditions to meet the infinite boundary conditions in the actual situation. Due to the shallow burial depth of the cavern, the self-weight of the rock mass is ignored. The rock mass and explosives are set as 3D Solid164, and the rock bolt is set as Beam161. The model is divided by a grid of $1 \mathrm{~cm}$ in size. 


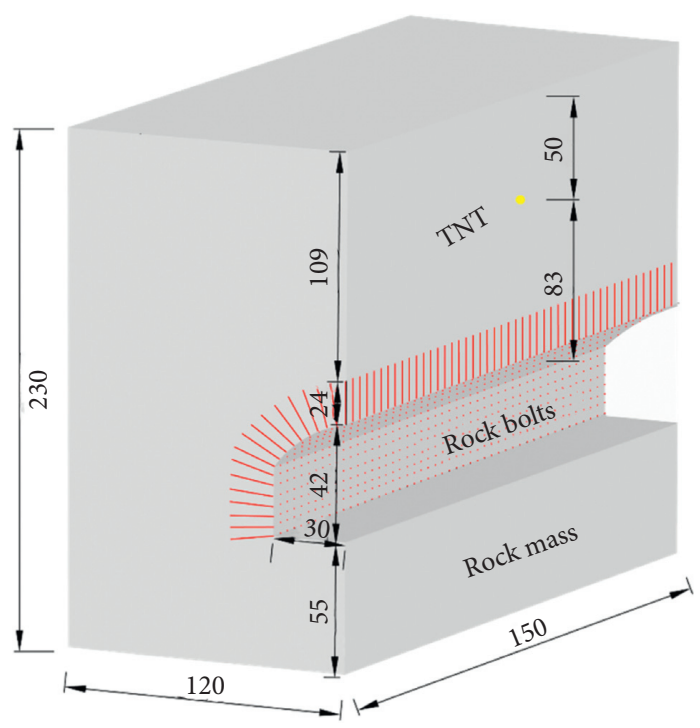

FIgURE 1: Dimensions for the test model (unit: $\mathrm{cm}$ ).

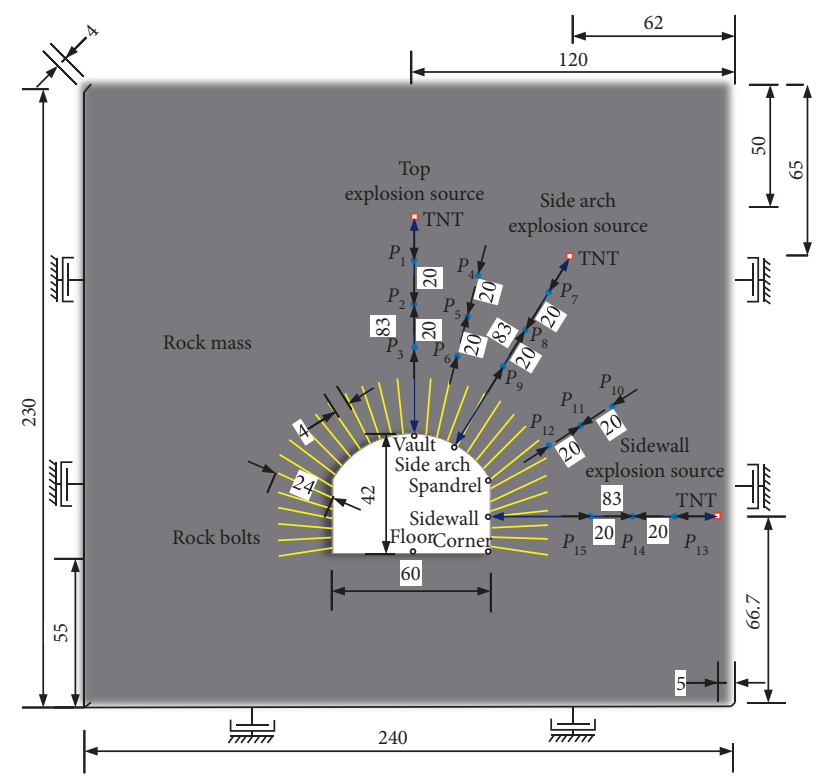

FIGURE 2: Model of numerical analysis (unit: $\mathrm{cm}$ ).

Table 1: Seven cases.

\begin{tabular}{|c|c|c|c|c|c|c|c|}
\hline \multirow{2}{*}{$\begin{array}{l}\text { Number of explosion sources } \\
\text { Case }\end{array}$} & \multicolumn{3}{|c|}{ One } & \multicolumn{3}{|c|}{ Two } & \multirow{2}{*}{$\begin{array}{c}\text { Three } \\
7\end{array}$} \\
\hline & 1 & 2 & 3 & 4 & 5 & 6 & \\
\hline Explosion & Top & Side arch & & $\begin{array}{c}\text { Top } \\
\text { Side arch }\end{array}$ & Top & Side arch & $\begin{array}{c}\text { Top } \\
\text { Side arch }\end{array}$ \\
\hline Source location & & & Sidewall & & Sidewall & Sidewall & Sidewall \\
\hline
\end{tabular}

3.2.1. Surrounding Rock. To date, scholars have developed many constitutive models that can represent the surrounding rock damage, such as the HJC model, TCK model, CSCM model, RHT material model, and so on. After consulting the literature, it is found that the HJC model fails to fully consider the tensile damage $\mathrm{P}$ of the material when describing the material damage [31]. The TCK model can well describe the tensile damage of the material, but it cannot indicate the compression damage [32]. The CSCM model can only describe the tensile and compressive damage of concrete under low confining pressures [33]. The RHT model improves the above shortcomings and can comprehensively reflect the compression and tensile damage, strain rate effect, strain hardening, softening, and failure 
phenomena of the surrounding rock $[34,35]$. Because the surrounding rock in this paper needs to consider the tensile and compressive damage at the same time, after a lot of attempts and comparative analysis, the RHT model is finally selected to simulate the rock mass.

The RHT model is divided into three stages: elastic stage, linear strengthening stage, and damage softening stage, as shown in Figure 3(a). When the equivalent stress $\bar{\sigma} \leq \sigma_{\text {elastic }}$, the model is in the elastic stage, and the elastic limit surface is the starting point of material plastic deformation. When $\sigma_{\text {elastic }} \leq \bar{\sigma} \leq \sigma_{\text {fail }}$, the material is in the linear strengthening stage, which is used to characterize the strain hardening effect of the material. In this stage, the material produces plastic deformation and transitions from the elastic limit surface to the failure surface. When $\bar{\sigma} \geq \sigma_{\text {fail }}$, the material is in the damage softening stage, and the failure stress of the material decreases to the residual stress with the accumulation of damage. The above three stages involve the equations of elastic limit surface, failure surface, and residual strength surface, which are related to pressure and are used to describe the variation law of material strength under impact loading, as shown in Figure 3(b).

The equivalent force strength of failure surface $\sigma_{\text {fail }}$ is the equation of normalized pressure $P$, Lode angle $\theta$, and strain rate $\dot{\varepsilon}$.

$$
\sigma_{\text {fail }}=Y_{T X C}^{*}(P) R_{3}(\theta) F_{\text {rate }}(\dot{\varepsilon}),
$$

where $Y^{*} \operatorname{TXC}(P)$ is the compressive meridian strength, $R_{3}(\theta)$ is the Lode angle factor, and $F_{\text {rate }}(\dot{\varepsilon})$ is the dynamic enhancement factor of strain rate.

$$
\begin{aligned}
& Y_{T X C}^{*}(P)=A\left[P^{*}-P_{\text {spall }}^{*} F_{\text {rate }}(\dot{e})\right]^{N} \\
& F_{\text {rate }}(\dot{\varepsilon})=\left\{\begin{array}{l}
\left(\frac{\dot{\varepsilon}}{\dot{\varepsilon}_{0}}\right)^{\alpha}>\frac{f_{c}}{3}, \dot{\varepsilon}_{0}=30 \times 10^{-6} s^{-1}, \\
\left(\frac{\dot{\varepsilon}}{\dot{\varepsilon}_{0}}\right)^{\delta}>\frac{f_{c}}{3}, \dot{\varepsilon}_{0}=3 \times 10^{-6} s^{-1},
\end{array}\right. \\
& R_{3}(\theta)=2\left(1-Q_{2}^{2}\right) \cos \theta+\left(2 Q_{2}-1\right) \times\left[4\left(1-Q_{2}^{2}\right) \cos ^{2} \theta+5 Q_{2}^{2}-4 Q_{2}\right]^{1 / 2} g \\
& \times\left[4\left(1-Q_{2}^{2}\right) \cos ^{2} \theta+\left(1-2 Q_{2}\right)^{2}\right]^{-1} \text {. } \\
& \theta=\frac{\cos ^{-1}\left(3 \sqrt{3} J_{3} / 2 J_{2}\right)}{3}, \theta \in\left[0, \frac{\pi}{3}\right] . \\
& Q_{2}=\frac{r_{t}}{r_{c}}=Q_{2,0}+B_{Q} P^{*}
\end{aligned}
$$

where $P_{\text {spall }}^{*}$ is the fracture strength of the normalized layer; $r_{t}, r_{c}$ are, respectively, the deviator stress at the meridian; $B_{Q}$ is the pressure influence parameter; $J_{2}$ is the second invariant, and $J_{3}$ is the third invariant; $A, N, \alpha, \delta, Q_{2,0}$ are material constants.
The elastic limit surface is derived from the failure stress of the failure surface, shown as follows:

$$
\sigma_{\mathrm{el}}^{*}=\sigma_{\mathrm{eq}}^{*} F_{\mathrm{el}} F_{\text {cap }} .
$$




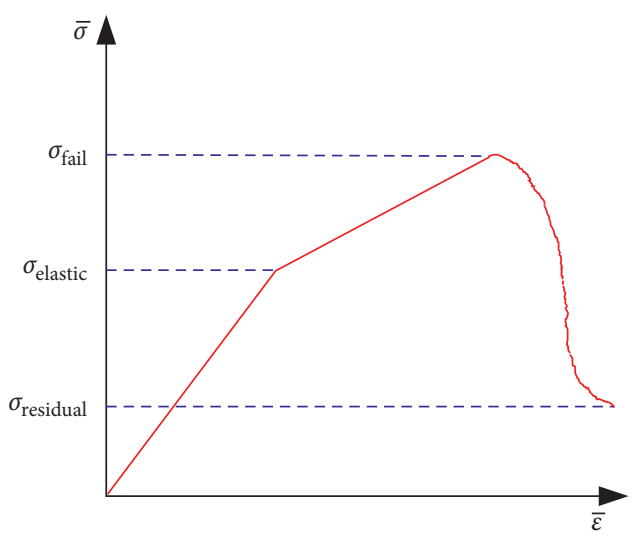

(a)

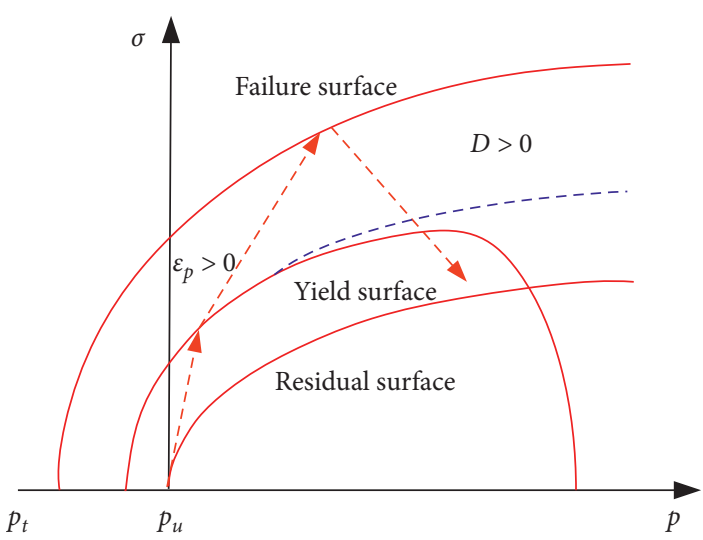

(b)

Figure 3: The RHT model. (a) Three phases of the RHT constitutive. (b) Stress limit surfaces and loading scenarios.

Among them, $F_{\text {elastic }}$ is the elastic scaling function, and $F_{\text {cap }}$ is the "cap" function.

$$
\begin{gathered}
F_{e l}= \begin{cases}R_{c}, & P \geq \frac{f_{c, \mathrm{el}}}{3}, \\
\frac{\left(P+f_{t, \mathrm{el}} / 3\right)}{\left(\left(f_{c, \mathrm{el}} / 3\right)+\left(f_{t, \mathrm{el}} / 3\right)\right)} R_{c}+\frac{\left(P-f_{c, \mathrm{el}} / 3\right)}{\left(\left(-f_{t, \mathrm{el}} / 3\right)+\left(f_{c, \mathrm{el}} / 3\right)\right)} R_{t}, & \frac{-f_{t, \mathrm{el}}}{3}<P<\frac{f_{c, \mathrm{el}}}{3}, \\
R_{t}, & P \leq \frac{-f_{t, \mathrm{el}}}{3},\end{cases} \\
F_{\text {cap }}= \begin{cases}1, & P \leq P_{u}=\frac{f_{c}}{3}, \\
\sqrt{1-\left[\frac{\left(P-P_{u}\right)}{\left(P_{0}-P_{u}\right)}\right]^{2}}, & P_{u}<P<P_{0}, \\
0, & P \leq P_{u}=\frac{f_{c}}{3},\end{cases}
\end{gathered}
$$

where $R_{t}$ and $R_{c}$ are material parameters; $f_{t, \mathrm{el}}$ is the elastic limit of uniaxial tensile; $f_{c, \text { el }}$ is the elastic limit of uniaxial compression; $P_{0}$ is the pressure when the pore begins to compress; and $f_{c}$ is the uniaxial compressive strength.

The material does not cumulative damage in either the elastic stage or the linear strengthening stage. Only when the stress exceeds the failure stress and enters the damage softening stage, the damage starts to accumulate. The damage index $D$ is the ratio of cumulative equivalent plastic strain increment to ultimate failure equivalent plastic strain.

$$
\begin{gathered}
0 \leq D=\sum \frac{\Delta \varepsilon_{P}}{\varepsilon_{P}^{\text {failure }}} \leq 1, \\
\varepsilon_{P}^{\text {failure }}=D_{1}\left(P *-P_{\text {spall }}^{*}\right)^{D_{2}} \geq \varepsilon_{p}^{m},
\end{gathered}
$$

where $\Delta \varepsilon_{P}$ is equivalent plastic strain increment, $D_{1}$ and $D_{2}$ are material parameters, and $\varepsilon_{p}^{m}$ is the minimum equivalent plastic strain when the material fails.

When the stress exceeds the failure stress, the material is completely destroyed without deflection stress. However, due to the effect of confining pressure, there is friction between the broken parts, and the material can continue to bear the shear stress. The RHT model introduces the phenomenon of residual stress surface expression, and its equivalent stress intensity is

$$
\sigma_{\text {residual }}=A_{f}\left(P^{*}\right)^{n_{f}},
$$

where $A_{f}$ is the residual stress intensity parameter and $n_{f}$ is the residual stress intensity index. 
In this paper, several parameters of the RHT model are obtained by tests [30], and the test parameters are referenced from the literature [36] and adjusted appropriately, as shown in Table 2.

3.2.2. TNT. In this paper, the highly explosive material model $*$ MAT_HIGH_EXPLOSIVE_BURN [37] is used to describe TNT explosives whose detonation is defined by the Jones-Wilkins-Lee (JWL) equation of state [38].

The relationship between pressure and specific volume is as follows:

$$
P=A\left(1-\frac{\omega}{R_{1} V}\right) e^{-R_{1} V}+B\left(1-\frac{\omega}{R_{2} V}\right) e^{-R_{2} V}+\frac{\omega E_{0}}{V}
$$

where $A, B, R_{1}, R_{2}$, and $\omega$ are material constants; $P$ is the pressure; $V$ is the relative volume; and $E_{0}$ is the initial specific internal energy.

3.2.3. Rock Bolts. In the test, aluminum bars are employed to simulate the rock bolts. Considering the elastic-plastic properties of aluminum bars, the isotropic elastic-plastic model *MAT_PLASTIC_KINEMATIC [37] is used to describe the rock bolts in the calculation model. Table 3 lists the input parameters for explosives and rock bolts in LS-DYNA. The parameters of the rock bolts are obtained from the test [30], and the explosive parameters are referenced from the literature [38].

\section{Results and Discussion}

4.1. Comparative Analysis of Test and Numerical Results. To verify the accuracy of the simulation results, the stress time curves of the simulated and test models in the same position in case 1 are compared. Figure 4 shows the stress time curves of $P_{1}, P_{2}$, and $P_{3}$ measuring points (as shown in Figure 2) at $0.2 \mathrm{~m}, 0.4 \mathrm{~m}$, and $0.6 \mathrm{~m}$ directly below the explosion source, where the positive value is the compressive stress and the negative value is the tensile stress. It can be seen from Figure 4 that several stress time curves first rise rapidly to the peak value, then gradually decrease and tend to be stable. The peak pressure of three measuring points in the numerical simulation is slightly larger than the peak of measuring points at the same positions in the test, but it is still within the same order of magnitude. However, the stress curves in the test rise later than those in the simulation, indicating that the stress in the test reaches the measuring point later than it does in the simulation.

The stress wave attenuation formula in Fundamentals of protective design for conventional weapons [39] is widely used in the study of stress wave propagation characteristics. The formula is as follows:

$$
P_{\max }=c\left(\frac{R}{W^{1 / 3}}\right)^{-n}
$$

where $P_{\max }$ is the peak pressure; $R / W^{1 / 3}$ is the scaled distance; $R$ is the distance from the explosion source; $W$ is the

\begin{tabular}{|c|c|}
\hline Parameter & Value \\
\hline Mass density RO $\left(\mathrm{kg} / \mathrm{m}^{3}\right)$ & 1700 \\
\hline Initial porosity ALPHA & 0.0 \\
\hline Crush pressure PEL (GPa) & 0.0 \\
\hline Compaction pressure PCO (GPa) & 0.36 \\
\hline Hugoniot polynomial coefficient $A 1(\mathrm{GPa})$ & 2.1162 \\
\hline Hugoniot polynomial coefficient $A 2(\mathrm{GPa})$ & 2.3748 \\
\hline Hugoniot polynomial coefficient $A 3(\mathrm{GPa})$ & 0.5424 \\
\hline Parameter for polynomial EOS $B 0$ & 1.22 \\
\hline Parameter for polynomial EOS $B 1$ & 1.22 \\
\hline Parameter for polynomial EOS $T 1(\mathrm{GPa})$ & 2.1162 \\
\hline Parameter for polynomial EOS $T 2(\mathrm{GPa})$ & 0.0 \\
\hline Elastic shear modulus SHEAR (GPa) & 1.002 \\
\hline Compressive strength FC (MPa) & 2.1 \\
\hline Relative tensile strength $\mathrm{FT}^{*}$ & 0.1 \\
\hline Relative shear strength FS* & 0.18 \\
\hline Failure surface parameter $A$ & 1.6 \\
\hline Failure surface parameter $N$ & 0.61 \\
\hline Lode angle dependence factor $Q 0$ & 0.6805 \\
\hline Lode angle dependence factor $B$ & 0.0105 \\
\hline Porosity exponent NP & 0.0 \\
\hline Reference compressive strain-rate EOC & $3.0 E-11$ \\
\hline Reference tensile strain rate EOT & $3.0 E-12$ \\
\hline Break compressive strain rate $\mathrm{EC}$ & $3.0 E+19$ \\
\hline Break tensile strain rate $\mathrm{ET}$ & $3.0 E+19$ \\
\hline Compressive strain rate dependence exponent BETAC & 0.032 \\
\hline Tensile strain rate dependence exponent BETAT & 0.036 \\
\hline Volumetric plastic strain fraction in tension PTF & 0.001 \\
\hline Compressive yield surface parameter GC* & 0.53 \\
\hline Tensile yield surface parameter $\mathrm{GT}^{*}$ & 0.7 \\
\hline Erosion plastic strain EPSF & 2.0 \\
\hline Shear modulus reduction factor XI & 0.5 \\
\hline Damage parameter $D 1$ & 0.04 \\
\hline Damage parameter $D 2$ & 1.0 \\
\hline Minimum damaged residual strain EPM & 0.01 \\
\hline Residual surface parameter AF & 1.6 \\
\hline Residual surface parameter NF & 0.61 \\
\hline Gruneisen gamma GAMMA & 0.0 \\
\hline
\end{tabular}

TABLE 2: The parameters for the RHT model of the rock mass.

charge masses; $c$ is a typical value, which depends on the properties of explosives and materials; and $n$ is the attenuation factor, which mainly depends on the properties of materials.

Figure 5 shows the fitting curve of the peak pressure and the scaled distance of each measuring point. It can be seen from Figure 5 that the shape of the fitting curve in the test and the simulation is relatively similar. The curve is relatively steep at first, and then becomes slower. This indicates that the attenuation speed of the peak pressure of the surrounding rock is relatively large when the scaled distance is small. With the increasing of the scaled distance, the attenuation speed of the peak pressure decreases gradually. Meanwhile, it can be observed that the attenuation factor of the fitting curve in the simulation is 1.2712, which is slightly smaller than the 1.3283 in the test, indicating that the attenuation speed of the stress wave in the test is greater than that in the simulation.

The analysis believes that the above phenomenon is related to the geological conditions of the surrounding rock. In the numerical simulation, the surrounding rock is 
TABLE 3: LS-DYNA material type, properties, and EOS input data.

\begin{tabular}{|c|c|c|c|c|c|c|c|}
\hline \multirow{3}{*}{$\begin{array}{l}\text { Material } \\
\text { Rock bolt }\end{array}$} & \multicolumn{7}{|c|}{ LS-DYNA material type, properties, and EOS input data (units: $\mathrm{cm}, \mathrm{g}, \mu \mathrm{s}$ ) } \\
\hline & \multicolumn{7}{|c|}{${ }^{*}$ MAT_PLASTIC_KINEMATIC } \\
\hline & $\mathrm{RO}$ & E & $\mathrm{PR}$ & SIGY & \multicolumn{3}{|c|}{ ETAN } \\
\hline & 2.72 & 0.76 & 0.34 & 0.00145 & $2.50000 E-$ & & \\
\hline \multirow{6}{*}{ TNT } & \multicolumn{7}{|c|}{ "MAT_HIGH_EXPLOSIVE_BURN } \\
\hline & RO & $\mathrm{D}$ & PCJ & & & & \\
\hline & 1.63 & 0.693 & 0.27 & & & & \\
\hline & ${ }^{*}$ EOS_JWL & & & & & & \\
\hline & A & $B$ & $R_{1}$ & $R_{2}$ & OMEG & E0 & V \\
\hline & 3.71 & 0.0743 & 4.15 & 0.95 & 0.3 & 0.07 & 1.0 \\
\hline
\end{tabular}

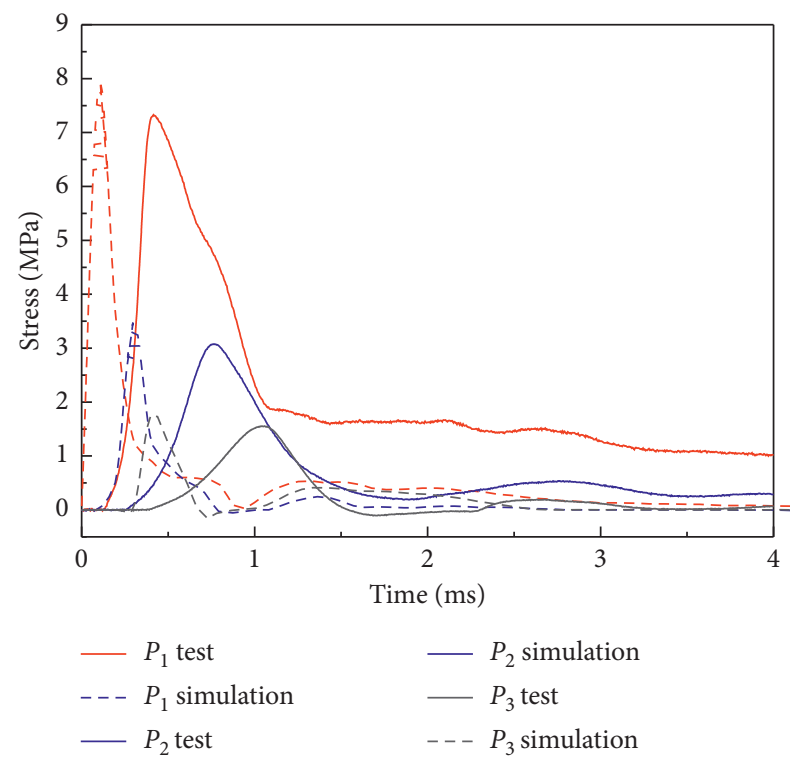

Figure 4: Comparison of stress time curves of rock elements between analysis and test.

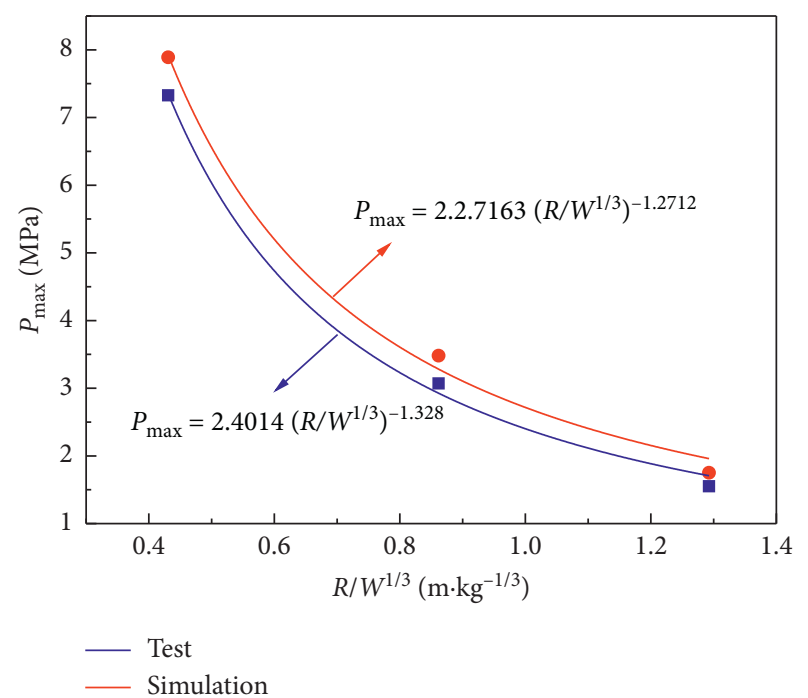

Figure 5: Relation between the peak compression stress and scaled distance. regarded as an isotropic medium, and the model in the test is made of cement mortar. During the test construction process, the compaction of the surrounding rock is carried out in layers, leaving many layers, which increases the energy consumed during the propagation of the stress wave, accelerates the attenuation speed of the stress wave, and also slows down the propagation rate of the stress wave. Therefore, the peak pressure at the test measuring point is smaller than that at the same measuring position in the simulation, and the attenuation speed of the stress wave in the test is larger than that in the simulation. And, the reason why the stress wave curve rises first in the simulation is also explained. In summary, the numerical simulation results have high credibility.

4.2. Analysis of Peak Stress. To reveal the propagation law of the stress wave in the surrounding rock under multiple explosion sources, a measuring point is arranged every $20 \mathrm{~cm}$ on the line connecting the explosion source and the arch center. In addition, the measuring points are arranged in the middle of the two adjacent measuring points, as shown in Figure 2. In each case, 15 measuring points numbered $P_{1}-P_{15}$ are arranged. The peak pressure of each measurement point in the seven cases is shown in Table 4 . It can be seen from the three measuring points in the same direction that the peak pressure decreases with the increasing distance from the explosion source. Comparing case 1, case 2, and case 4 , it can be found that there is not much difference in the peak pressure of the measuring points on the line connecting the explosion source and the arch center in the cases of two explosion sources and a single explosion source. The main difference is in the middle of the two explosion sources. For example, the peak pressure of $P_{4}, P_{5}$, and $P_{6}$ measuring points in case 4 is $2.52,2.14$, and 2.88 times of the same measuring point in case 1 . Similarly, the peak pressure of $P_{4}$, $P_{5}$, and $P_{6}$ measuring points in case 4 is $2.61,2.05$, and 2.83 times of that of case 2 , respectively. Compared with case 2 , case 3 , and case 6 , it can also be found that the peak pressure of the measuring points in the direction of the connection between the explosion source and the arch center is not much different. The peak pressure of $P_{10}, P_{11}$, and $P_{12}$ in case 6 is increased by $76.8 \%, 74.5 \%$, and $114.2 \%$, respectively, compared with that at the same position in case 2 , and increased by $86.9 \%, 69.7 \%$, and $118.3 \%$, respectively, compared with that at the same position in case 3 . By comparing 
TABle 4: Peak compressive stress of the measuring points.

\begin{tabular}{|c|c|c|c|c|c|c|c|c|c|c|c|c|c|c|c|}
\hline \multirow{2}{*}{ Case } & \multicolumn{15}{|c|}{ Peak compressive stress $(\mathrm{MPa})$} \\
\hline & $P_{1}$ & $P_{2}$ & $P_{3}$ & $P_{4}$ & $P_{5}$ & $P_{6}$ & $P_{7}$ & $P_{8}$ & $P_{9}$ & $P_{10}$ & $P_{11}$ & $P_{12}$ & $P_{13}$ & $P_{14}$ & $P_{15}$ \\
\hline Case 1 & 7.89 & 3.84 & 1.75 & 5.75 & 3.21 & 1.52 & 2.64 & 2.25 & 1.38 & 1.24 & 1.27 & 1.29 & 1.04 & 1.17 & 1.32 \\
\hline Case 2 & 2.74 & 2.32 & 1.01 & 5.55 & 3.34 & 1.55 & 7.55 & 3.62 & 1.83 & 3.71 & 3.21 & 2.12 & 1.33 & 1.35 & 1.34 \\
\hline Case 3 & 0.92 & 1.11 & 1.17 & 1.08 & 1.13 & 1.68 & 1.29 & 1.31 & 2.01 & 3.51 & 3.33 & 2.08 & 7.63 & 4.61 & 2.85 \\
\hline Case 4 & 7.65 & 3.50 & 2.57 & 14.5 & 6.88 & 4.39 & 7.66 & 3.45 & 2.74 & 4.10 & 4.21 & 3.58 & 1.31 & 1.71 & 1.87 \\
\hline Case 5 & 7.65 & 3.57 & 2.51 & 5.86 & 3.18 & 1.79 & 2.63 & 2.19 & 1.92 & 4.58 & 3.72 & 2.36 & 7.75 & 4.69 & 2.92 \\
\hline Case 6 & 2.68 & 2.37 & 1.20 & 5.88 & 3.54 & 1.86 & 7.75 & 3.80 & 2.18 & 6.56 & 5.60 & 4.54 & 7.85 & 4.19 & 3.02 \\
\hline Case 7 & 7.55 & 3.66 & 2.59 & 14.7 & 6.80 & 4.49 & 7.70 & 3.52 & 2.63 & 7.75 & 6.55 & 5.55 & 7.65 & 4.62 & 3.10 \\
\hline
\end{tabular}

case 1 , case 2 , case 3 , and case 7 , it can be found that the peak pressure of the measuring points on the line connecting the explosion source and the arch center in case 7 is close to the peak pressure of the measuring points at the same position in the case of single explosion source. In case 4 , case 6 , and case 7 , the peak pressure difference between the two explosion sources is very small. In general, the increasing explosion source number has little effect on the peak pressure on the line connecting the explosion source and the arch center. Due to the loading wave formed by the interaction of the stress wave, the influence of the increasing explosion source number on the peak pressure is mainly in the middle of the two explosion sources.

4.3. Analysis of Damage Evolution of the Surrounding Rock. From the damage evolution process of the surrounding rock, the specific reasons for the damage of the cavern can be seen, which has guiding significance for the antiexplosion design of the cavern. Representative case 1 , case 4 , and case 7 are selected from the seven cases to analyze the damage evolution process of the surrounding rock under a single explosion source, double explosion sources, and triple explosion sources.

4.3.1. Damage Evolution Process of the Surrounding Rock in Case 1. Figure 6 shows the damage evolution process of the underground cavern under the top explosion. Different colors in the figure correspond to different damage indexes. The closer the damage index is to 1 , the greater the damage, and 1 represents complete damage. Figure 6(a) shows the damage of the cavern at $0.3 \mathrm{~ms}$ after the explosion, from which it can be seen that the high temperature and high pressure of the explosion cause circular damage around the explosion source. At $0.4 \mathrm{~ms}$, a damaged strip is formed near the ground. This is because the compressive stress waves generated by the explosion propagate to the ground and reflect to form tensile stress waves. The tensile strength of the surrounding rock is relatively weak and tensile damage will occur. Similarly, when the compressive stress wave propagates to the free surface of the vault at $0.6 \mathrm{~ms}$, the surrounding rock around the vault also begins to produce tensile damage. The damage of the surrounding rock accumulates with the increasing repeated impact times and the subsequent stress wave will increase the damage degree of the damaged surrounding rock [40]. When the stress wave transmitted from the ground and the free surface of the vault meets the blast cavity formed by the explosion, it will reflect again. Due to the accumulation of damage, the radius of the damage circle around the explosion source becomes larger and larger, as shown in Figures 6(c) and 6(d). Besides, as time goes on, the damage zone near the surface expands to both sides of the model and explosion source, and the closer to the explosion source, the narrower the width of the damage zone becomes. With the increasing range of the stress wave propagating to the vault, the damage zone near the vault becomes larger and larger. At $0.8 \mathrm{~ms}$, horizontal and vertical damage zones are generated below the detonation source in Figure 6(e). Analysis believes that the tensile stress waves reflected from the ground and the vault meet and overlap here, increasing the tensile stress wave strength. With the propagation of the stress wave, the superimposed position of the tensile stress wave gradually moves to the sides and the vault, and the damage zone also gradually extends in these two directions, as shown in Figures 6(f) and $6(\mathrm{~g})$. Due to the decrease of the subsequent stress wave intensity, the damage of the surrounding rock of the cavern does not change after $2.2 \mathrm{~ms}$. It can be seen from Figure 6(h) that the surrounding rock near the ground is a serious damage zone and has been connected with the damage circle around the explosion source. The damage zone near the vault is distributed in an arched shape, and the damage of the surrounding rock in the reinforced area shows the characteristics of the distribution along the bolt direction. As the tensile strength of the rock mass in the nonreinforced area is weaker than that in the reinforced area, the damage degree of the rock mass at the junction of the reinforced and nonreinforced area increases significantly. Due to the diffraction and reflection of the stress wave, a slight vertical damage zone is formed in the middle of the cavern floor. The compressive stress wave caused by the explosion source diffracts through the cavern and reflects on the cavern floor, and a slight vertical damage zone is formed in the middle of the cavern floor.

4.3.2. Damage Evolution Process of the Surrounding Rock in Case 4. Figure 7 shows the damage evolution process of the underground cavern under the simultaneous top explosion and side arch explosion. In Figure 7(a), there is an obvious damage circle around the explosion source. At $0.4 \mathrm{~ms}$ and $0.5 \mathrm{~ms}$, the compressive stress caused by the explosion source on the side of the vault and side arch reflects on the ground to produce tensile damage zones. In Figure $7(\mathrm{~d})$, a 


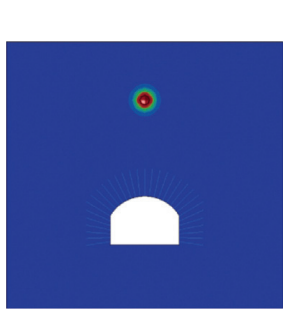

(a)

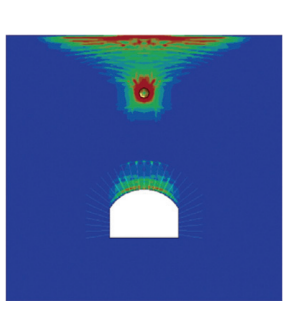

(d)

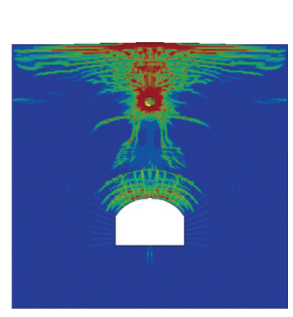

(g)

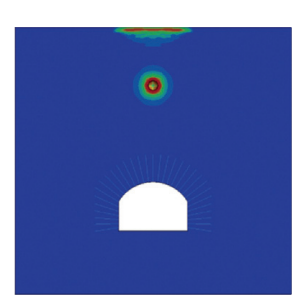

(b)

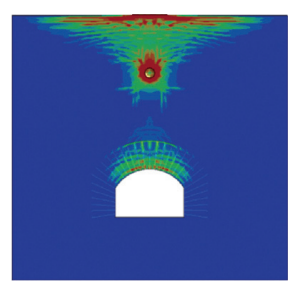

(e)

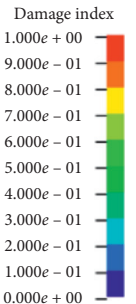

$1.000 e-01$
$0.000 e+00$

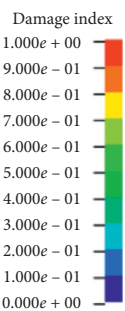

$1.000 e-01$
$0.000 e+00$

Damage index $1.000 e+00$ $9.000 e-01$ $8.000 e-01-$ $8.000 e-01$
$7.000 e-01$ $7.000 e-01$
$6.000 e-01$ $5.000 e-01$ $4.000 e-01$ $3.000 e-01$ $2.000 e-01$ $1.000 e-01$ $0.000 e+00$

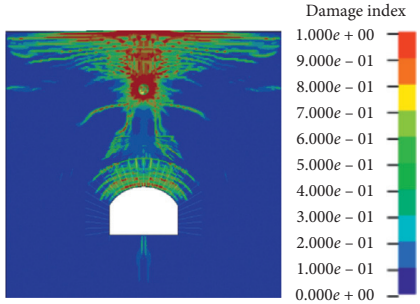

(h)

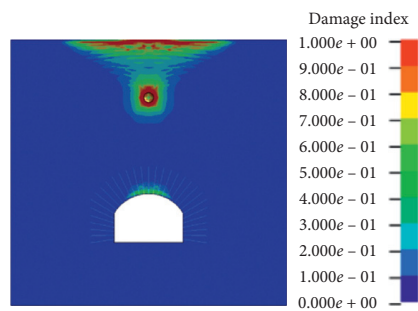

(c)

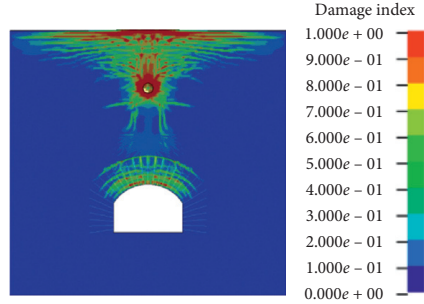

(f)

FiguRE 6: The damage evolution process of the underground cavern under the top explosion. (a) (t) $=0.3 \mathrm{~ms}$. (b) (t) $=0.4 \mathrm{~ms}$. (c) (t) $=0.6 \mathrm{~ms}$. (d) $(\mathrm{t})=0.7 \mathrm{~ms}$. (e) $(\mathrm{t})=0.8 \mathrm{~ms}$. (f) $(\mathrm{t})=1.0 \mathrm{~ms}$. (g) $(\mathrm{t})=1.6 \mathrm{~ms}$. (h) $(\mathrm{t})=2.2 \mathrm{~ms}$.

damage zone is generated between the vault and the side arch, and the damage degree of the middle part of the damage zone is obviously greater than that of other parts. This is because the compressive stress waves caused by the two explosion sources are superimposed here, and the strength of the stress wave increases obviously, so the damage to the surrounding rock is increased. Meanwhile, it can be observed that there is obvious damage in the connection direction of the two explosion sources, which is caused by the tensile stress reflected by the free surface of the blast cavity formed by the explosion. In the middle of the line connecting the two explosion sources, the damage degree is slightly higher due to the superposition of tensile stress waves reflected from the two blast cavities. With time, the damage of the surrounding rock caused by the stress wave generated by the two explosion sources is accumulating. In Figures $7(\mathrm{e})$ and $7(\mathrm{f})$, the damage around the arch has extended beyond the reinforced zone, and the damage near the ground has further extended downward. Besides, the damage of the surrounding rock on the line connecting the midpoint of the two explosion sources and the arch center is greater than that of other places. This is caused by the superposition of the tensile stress formed by the reflection of the compressive stress waves generated by the two explosion sources on the ground. At $1.5 \mathrm{~ms}$, the tensile stress wave formed by the reflection from the ground and cavern meets about $60 \mathrm{~cm}$ at the upper left of the cavern, resulting in a damage zone extending to the boundary of the model. In Figure 7(h), a damage zone inclined to the left is formed in the middle of the cavern floor.

4.3.3. Damage Evolution Process of the Surrounding Rock in Case 7. Figure 8 shows the damage evolution process of the underground cavern under the simultaneous top explosion, side arch explosion, and sidewall explosion. In Figures 8(b) and $8(\mathrm{c})$, the shape and cause of the damage zone near the ground are the same as the damage here in case 4 . At $0.6 \mathrm{~ms}$, the compressive stress waves generated by the three blasting sources all propagate to the free surface of the cavern, and the tensile damage zone is formed at the arch and sidewall. With the propagation of the stress wave, at $1.0 \mathrm{~ms}$, the damage zone near the ground expands downward, and the damage zone around the arch and sidewall has exceeded the reinforced area, reaching the nonreinforced area. The damage at the middle position of the top and side arch explosion sources increases significantly. In addition, when the stress waves reflected from the surface pass through the explosion sources, the damage around the blast cavities will be further expanded due to the accumulation of damage. A slight vertical damage zone is formed between the side arch explosion source and the sidewall explosion source due to the superposition of the tensile wave reflected by the ground and the sidewall. At the right foot of the sidewall, there is a 


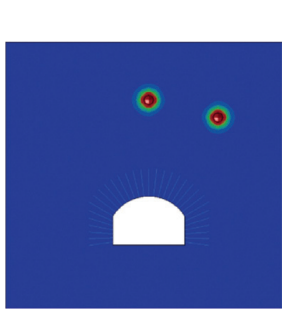

(a)

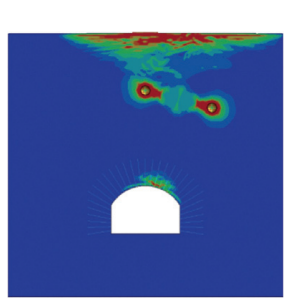

(d)

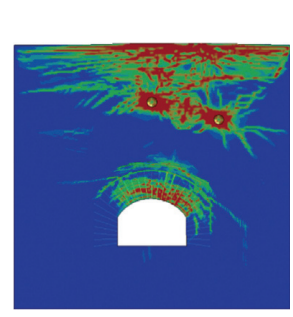

(g)

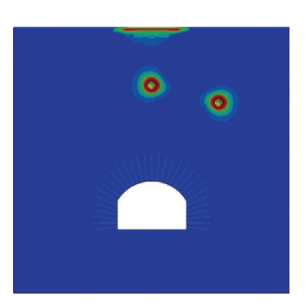

(b)

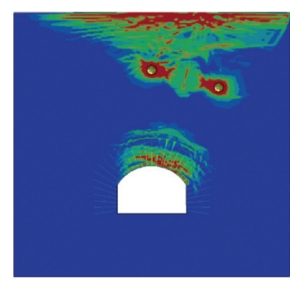

(e)

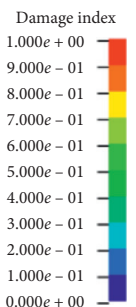

$1.000 e-01$
$0.000 e+00$
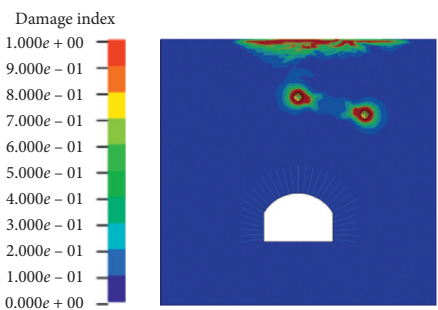

Damage index

$1.000 e+00$

$9.000 e-01$

$8.000 e-01$

$7.000 e-01-$

$6.000 e-01-$

$5.000 e-01-$

$4.000 e-01$

$3.000 e-01$

$\left.\begin{array}{l}2.000 e-01 \\ 1.000 e-01\end{array}\right]$

$0.000 e+00$

(c)

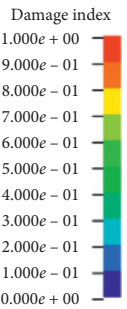

$1.000 e-01$
$0.000 e+00$

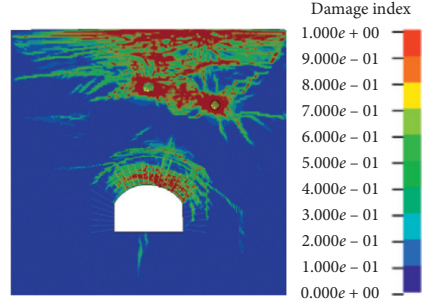

(h)

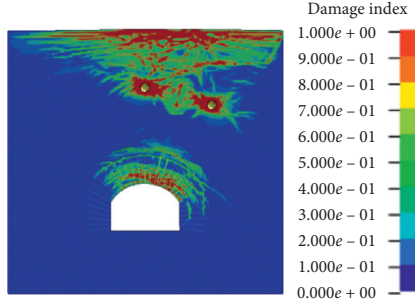

(f)

Figure 7: The damage evolution process of the underground cavern under the simultaneous top explosion and side arch explosion. (a) $t=0.3 \mathrm{~ms}$. (b) $t=0.4 \mathrm{~ms}$. (c) $t=0.5 \mathrm{~ms}$. (d) $t=0.6 \mathrm{~ms}$. (e) $t=0.8 \mathrm{~ms}$. (f) $t=1.0 \mathrm{~ms}$. (g) $t=1.5 \mathrm{~ms}$. (h) $t=2.2 \mathrm{~ms}$.

damage zone extending to the left, which is caused by the compressive stress wave generated by the sidewall explosion reflecting on the floor. In Figure $8(\mathrm{f})$, the stress wave reflected from the side arch and the sidewall blast cavity meets, which further increases the damage zone between the two explosion sources. Besides, the superposition of the tensile stress wave from the ground and the stress wave reflected from the blast cavity on the sidewall further increases the damage range between the side arch and the sidewall explosion sources. At about $60 \mathrm{~cm}$ on the upper left of the vault, a superposition of tensile stress waves reflected from the ground and the free surface of the cavern forms a damage zone. After $2.2 \mathrm{~ms}$, the damage of the surrounding rock tends to be stable.

\subsubsection{Comparative Analysis of the Surrounding Rock Damage} in Seven Cases. To study the damage distribution characteristics of the surrounding rock under explosions, Figure 9 shows the damage distribution of the surrounding rock in seven cases. According to the causes of the surrounding rock damage, the damage is divided into seven zones. Zone 1 is the surrounding rock damage caused by high temperature and high pressure caused by explosion source; zone 2 represents the damage formed by tensile waves reflected by the ground surface; zone 3 represents the damage formed by tensile waves reflected by the free surface of the cavern; the damage in zone 4 is caused by the reflection of stress waves from the ground and the free surface when they meet the blast cavity; zone 5 is the damage zone formed by the superposition of tensile stress waves reflected from the ground and the free surface of the cavern; the damage in zone 6 is formed by the superposition of the stress waves reflected by the two blasting cavities; The damage in zone 7 is formed by the encounter of the tensile stress waves reflected from the ground and the sidewall blast cavity.

By comparing Figures $9(\mathrm{a})-9(\mathrm{~g})$, it can be seen that the damage distribution range is the widest in the case of three explosion sources, followed by the case of two explosion sources, and the single detonation source case is the smallest. The damage range of zone 1 is basically the same in the seven cases, and the radius of the damage circle is roughly three times the charging radius. The distribution range and damage degree of zone 2 near the ground surface decrease with the increasing distance between the explosion source and the ground and increase with the increasing explosion source numbers. In the single explosion source cases, most of the damage in zone 3 is distributed toward the direction of the explosion source, and the damage degree is the largest on the line connecting the explosion source and arch center. Due to the stress wave diffraction and the tensile stress wave generated by the reflection of the floor, damage zone 3 also exists near the floor. When the explosion source increases to two or three, the damage is the most serious on the line connecting the middle 


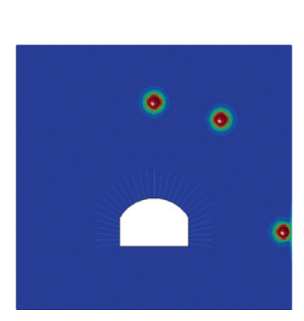

(a)

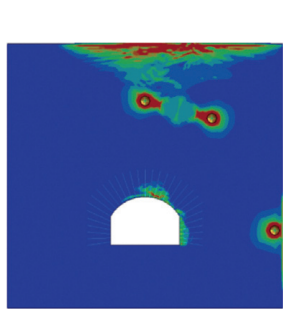

(d)

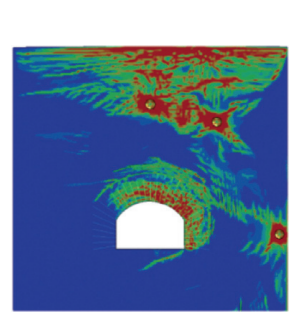

(g)

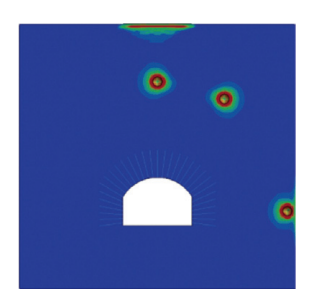

(b)

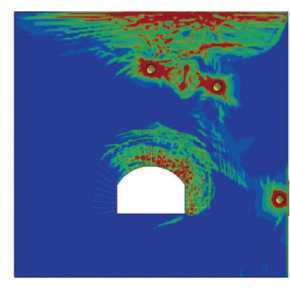

(e)

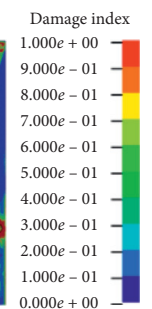

$0.000 e+00$

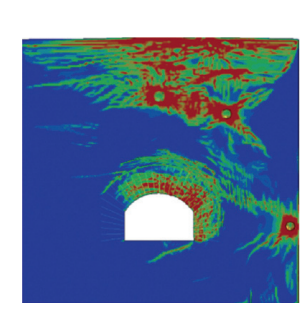

(h)

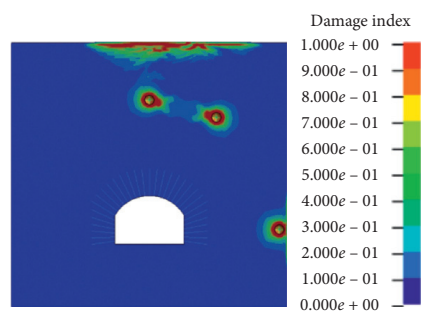

(c)
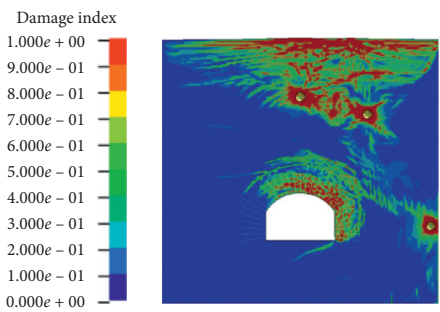

Damage index $1.000 e+00$ $9.000 e-01$ $8.000 e-01-$ $7.000 e-01$ $7.000 e-01$
$6.000 e-01$ $5.000 e-01$ $4.000 e-01=$ $3.000 e-01$ $2.000 e-01$ $1.000 e-01$ $0.000 e+00$ (f)
Damage index

$1.000 e+00$

$9.000 e-01$ $8.000 e-01-$ $7.0000-01$ $6.000 e-01$ $5.000 e-01-$ $4.000 e-01$ $3.000 e-01$ $2.000 e-01-$ $1.000 e-01$ $0.000 e+00$

FIGURE 8: The damage evolution process of the underground cavern under the simultaneous top explosion, side arch explosion, and sidewall explosion. (a) $t=0.3 \mathrm{~ms}$. (b) $t=0.4 \mathrm{~ms}$. (c) $t=0.5 \mathrm{~ms}$. (d) $t=0.6 \mathrm{~ms}$. (e) $t=1.0 \mathrm{~ms}$. (f) $t=1.2 \mathrm{~ms}$. (g) $t=1.5 \mathrm{~ms}$. (h) $t=2.2 \mathrm{~ms}$.

position of two explosion sources and the arch center. This is caused by the superposition of tensile stress formed by the two explosion sources. In all cases, the distribution range and degree of damage in zone 4 near the same explosion source are similar, which indicates that damage in zone 4 is less affected by the number of explosion sources. It can be seen from Figures 9(a)-9(c) that the position of damage zone 5 gradually moves upward as the explosion source position moves downward. The distribution of damage in zone 5 in multiple explosion sources is different from that in the corresponding single explosion source, and this situation is more obvious in case 4 and case 7 . Analysis indicates that the distance between the vault and the side arch explosion source in case 4 and case 7 is relatively close. When the stress wave reflected from the ground passes through damage zone 1, the stress wave energy attenuation increases and the superposition of tensile stress waves is also difficult to cause serious damage to the surrounding rock. In case 5 and case 6 , the distance between the vault and the sidewall explosion source is far, and the attenuation of the stress wave propagation process is similar to the corresponding single explosion source. Damage in zone 6 only appears in the case of two explosion sources and three explosion sources and does not exist in the single explosion source case and is mainly distributed in the middle area of the two explosion sources. Damage zone 7 only exists in the presence of the sidewall explosion source, mainly distributed near the right arch of the cavern, and its damage degree is low.
It can be seen from Figure 9 that the damage zones 2-7 occupy most of the surrounding rock damage, and the damage zones 2-7 are caused by the tensile stress wave and superposition of the tensile stress wave. Therefore, the damage of the surrounding rock is mainly caused by the tensile stress wave reflected from the free surfaces and the superposition of the tensile stress wave.

In general, the damage of the surrounding rock in the case of multiple explosion sources is not a simple addition of the damage to the surrounding rock of the corresponding single explosion source. The main difference is that in the single explosion source case, there is no damage zone formed by the superposition of stress waves reflected from blasting cavities. The damage zone formed by the superposition of the stress waves reflected from the ground and the free surface of the cavern is also obviously different from that of the single explosion source due to the increase of the explosion source number. Besides, when the buried depth of the cavern increases, the tensile stress intensity generated by the ground reflection will gradually decrease, and zones $2,4,5$, and 7 will gradually disappear. It can be seen that the increase in the buried depth of the cavern can reduce the damage of the ground reflected stress wave to the surrounding rock.

\subsection{Analysis of Circumferential Peak Stress of the Cavern Wall.}




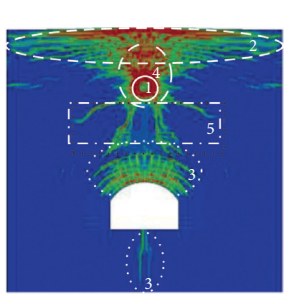

(a)

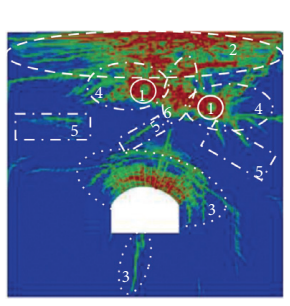

(d)
Damage index $1.000 e+00]$
$9.000 e-01]$ $9.000 e-01-$ $8.000 e-01-$ $7.000 e-01$ $6.000 e-01$ $5.000 e-01$ $4.000 e-01-$ $3.000 e-01-$ $2.000 e-01$ $1.000 e-01$ $0.000 e+00$

Damage index $1.000 e+00$ $9.000 e-01$ $8.000 e-01$ $8.000 e-01$ $7.000 e-01$ $6.000 e-01$ $5.000 e-01$ $4.000 e-01$ $3.000 e-01$ $1.000 e-01$ $0.000 e+00$

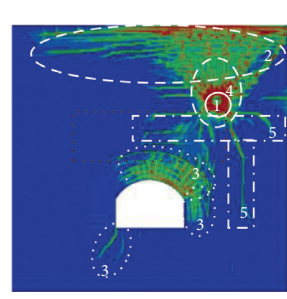

(b)

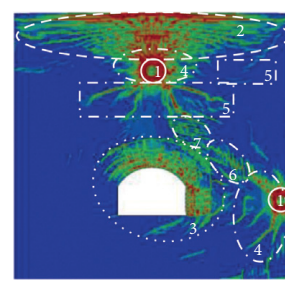

(e)

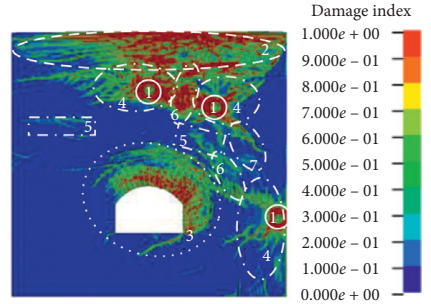

(g)
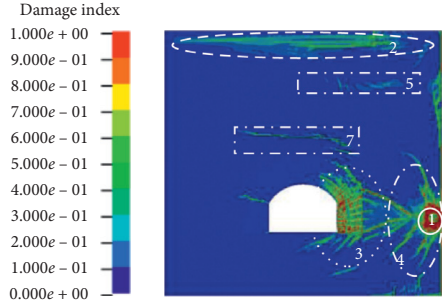

Damage index

1.000e+ 00

$9.000 e-01$

$.000 e-01-$

$7.000 e-01$

$6.000 e-01-$

$5.000 e-01-$

$.000 e-01$

$.000 e-01$

$2.000 e-01$

$1.000 e-01$

(c)
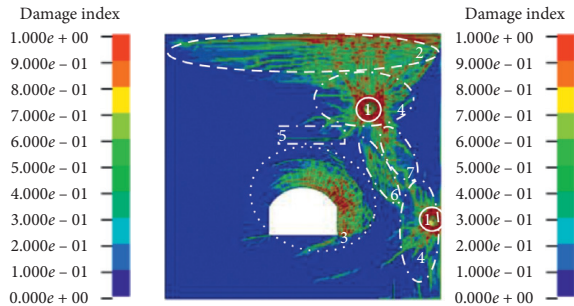

(f)

Figure 9: Damage distribution in seven cases. (a) Case 1. (b) Case 2. (c) Case 3. (d) Case 4 . (e) Case 5. (f) Case 6. (g) Case 7.

The circumferential strain of the cavern wall can reflect the circumferential stress of the cavern wall, which has important reference significance for analyzing the anti-blast performance of the cavern. Twenty-four circumferential strain measuring points $\left(\varepsilon_{1}-\varepsilon_{24}\right)$ are arranged on the cavern wall, as shown in Figure 10.

Figure 11 shows the peak circumferential strain at each measuring point of the cavern wall in the seven cases. The absolute value at each measuring point represents the magnitude of the strain. A positive value represents tensile strain, and a negative value represents compressive strain. It can be seen from Figure 11 that the peak circumferential strain from the vault to the side arch is all tensile. The reason is that the vault will produce downward displacement under explosion, and the surrounding rock around the vault is transversely tensioned, so there is tensile strain near the vault. When the explosion source near the sidewall exists, the sidewall will also produce tensile circumferential strain. This phenomenon is caused by the stress wave generated by the sidewall explosion that propagates to the sidewall, The surrounding rock near the sidewall will produce displacement to the interior of the cavern. The surrounding rock here is vertically tensioned, so the surrounding rock produces tensile strain. Meanwhile, it can be found that in case 3 , case 5 , case 6 , and case 7 , where the sidewall explosion source exists, the circumferential strain at the floor is tensile. The main reason is that the floor will be squeezed by the right sidewall under the sidewall explosion, and the floor will

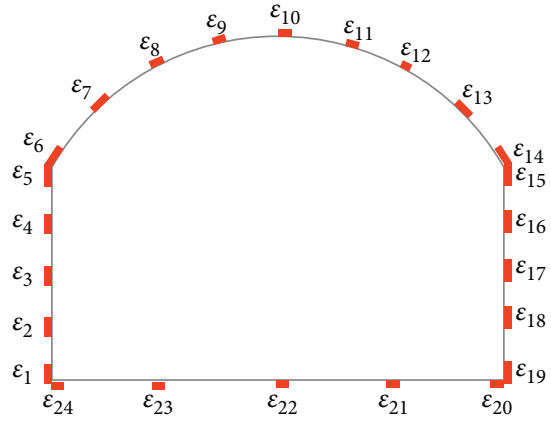

Figure 10: Arrangement of circumferential strain measuring points.

bulge upward and be stretched laterally, resulting in tensile strain. Consider that the tensile strength of the surrounding rock is far less than the compressive strength. Moreover, important instruments and equipment are often located on the floor. Therefore, it is necessary to avoid the sidewall explosion. When the explosion occurs only above the cavern, the sidewall and floor produce compressive circumferential strain. This is because the arch moves downward under the explosion above the cavern, squeezing the sidewall, and the sidewall compresses longitudinally, producing compressive circumferential strain. In the seven cases, from the vault to the spandrel, the strain changes from tension to compression, because the surrounding rock at the spandrel can be 


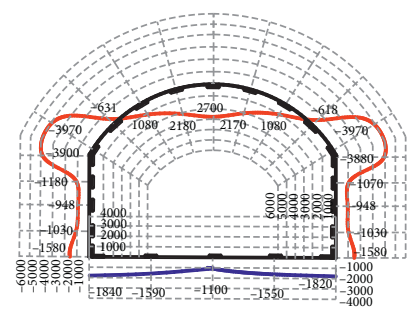

(a)

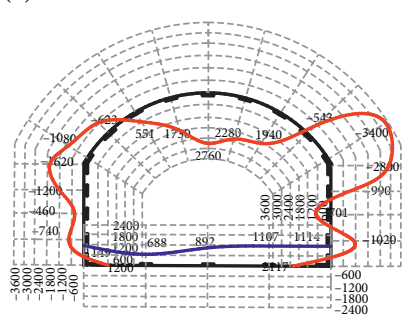

(e)

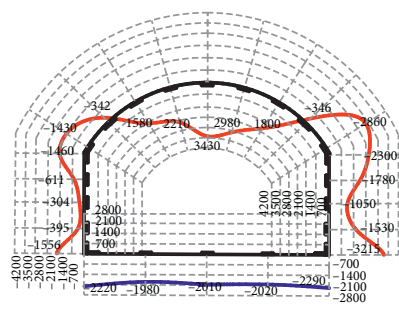

(b)

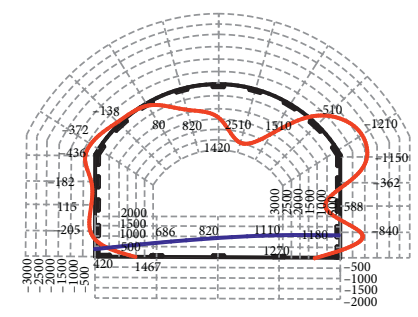

(c)

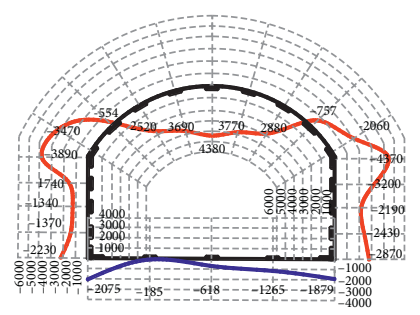

(d)

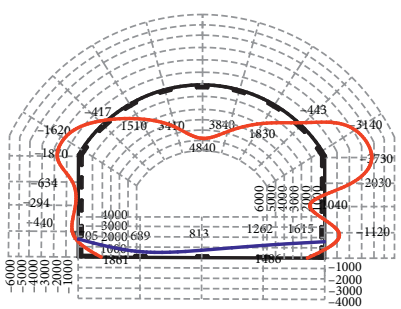

(f)

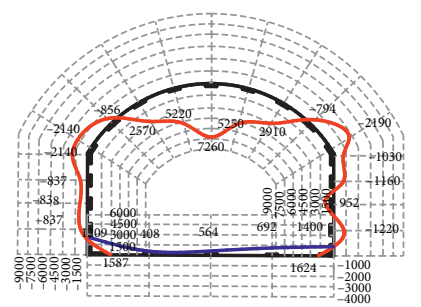

(g)

Figure 11: The peak circumferential strain distribution of the cavern wall (unit:10 ${ }^{-6}$ ). (a) Case 1. (b) Case 2. (c) Case 3. (d) Case 4. (e) Case 5. (f) Case 6. (g) Case 7.

supported by the lower surrounding rock, which makes it difficult to produce tensile circumferential strain here. In the seven cases, the absolute value of the peak circumferential strain from the vault to the spandrel first decreases and then increases. This is because the lack of effective support at the vault leads to greater circumferential strain in the surrounding rock, and the spandrel is at the junction of the two parts, which is prone to stress concentration. However, the circumferential strain of the spandrel is compressive, while the circumferential strain of the vault is tensile, so the vault is prone to damage under explosion. When the explosion source is presented at the sidewall, the tensile circumferential strain will be generated in the lower right corner of the sidewall, and the compressive circumferential strain is generated on the nonblasting cavern wall.

Comparing the case of multiple explosion sources and the corresponding single explosion source, it can be found that the absolute value of the peak circumferential strain at the measuring point on the line connecting the explosion source and arch center is larger than that of the corresponding single explosion source. For example, the peak circumferential strain of the measuring point $\varepsilon_{10}$ in case 4 is $62.22 \%$ larger than that of the measuring point $\varepsilon_{10}$ in case 1 , and the peak circumferential strain of the measuring point $\varepsilon_{12}$ in case 4 is $60 \%$ larger than that of the measuring point $\varepsilon_{12}$ in case 2 . The peak circumferential strains of measuring poinst $\varepsilon_{10}, \varepsilon_{12}$, and $\varepsilon_{17}$ are $168.8 \%, 58.11 \%$, and $27.8 \%$ larger than the corresponding single explosion source measuring points, respectively.

From the circumferential strain-time curve of the surrounding rock, the specific process of the circumferential strain of the surrounding rock can be seen. As there are many cases in numerical calculations, the most representative case 7 is selected here to analyze the circumferential strain-time curve of its measuring points. Figure 12 shows the circumferential strain-time curve of the measuring point $\left(\varepsilon_{1}-\varepsilon_{24}\right)$ in case 7 . The positive value in the figure is the tensile circumferential strain and the negative value is the compressive circumferential strain.

It can be seen from Figure 12 that when the stress wave propagates to the measuring point, the circumferential straintime curve will rapidly rise or drop to the peak, then there will be a fall or increase, and finally, gradually stabilize. The circumferential strain-time curve of the surrounding rock is not smooth. There is a period of falling in the rising process, and then it continues to rise, and there will also be a rising stage in the descending process. This is because the stress waves produced by the three explosions arrive at the measuring point at different times. It can be seen from Figure 12(a) that the circumferential strain of $\varepsilon_{1}$ changes from compressive to tensile, and the other four measuring points produce compressive circumferential strain. It can be seen from Figure 12(b) that from $\varepsilon_{6}$ to $\varepsilon_{9}$, the circumferential strain of the cavern wall changes from compressive to tensile, and with the decreasing distance from the measuring point to the vault, the compressive circumferential strain becomes smaller and the tensile circumferential strain becomes larger and larger. From the circumferential strain-time curves of several measuring points in Figure 12(c), it can be found that the values of the circumferential strain at measuring points $\varepsilon_{10}$, $\varepsilon_{11}$, and $\varepsilon_{12}$ are always positive. Therefore, the circumferential strain of the vault is tensile throughout the explosion process. In addition, the residual circumferential strain at measuring points $\varepsilon_{10}, \varepsilon_{11}$, and $\varepsilon_{12}$ is relatively large, indicating that the surrounding rock near the vault is in a state of large deformation. The measurement point $\varepsilon_{13}$ is in a state of alternating tension and compression, where the surrounding rock first produces tensile circumferential strain and then becomes compressive circumferential strain. Comparing Figures 12(c) and $12(\mathrm{~d})$, it can be seen that the absolute value of the circumferential strain of the sidewall is significantly smaller than that of the arch. The circumferential strain-time curve of 


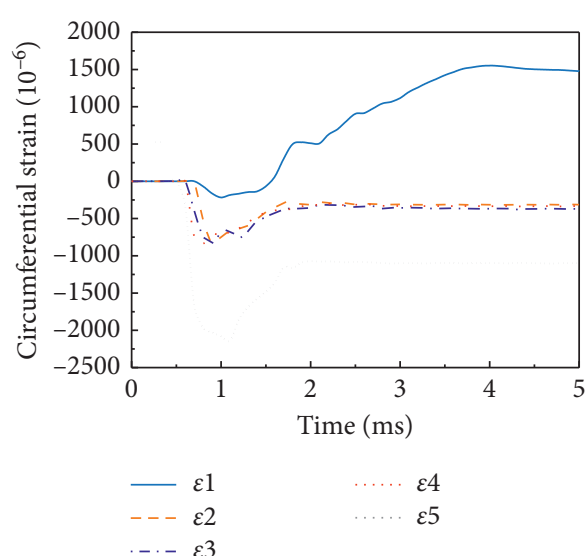

(a)

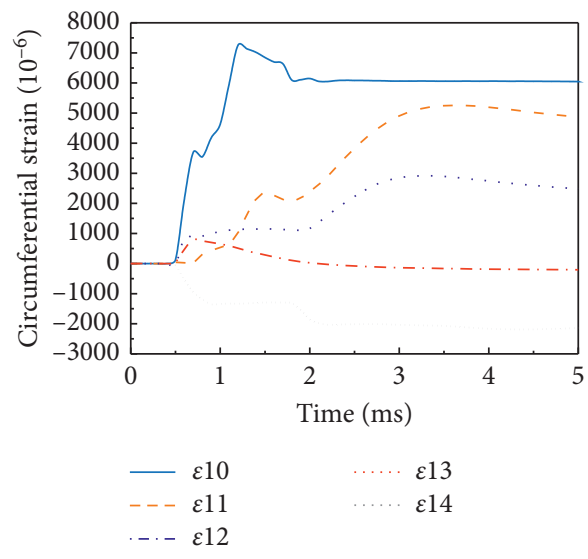

(c)

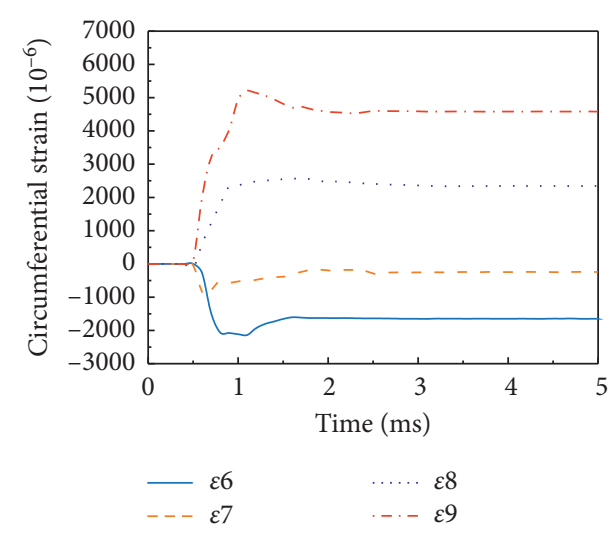

(b)

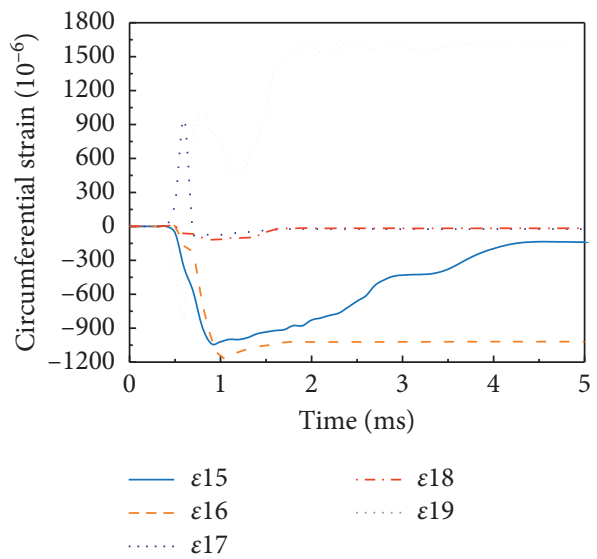

(d)

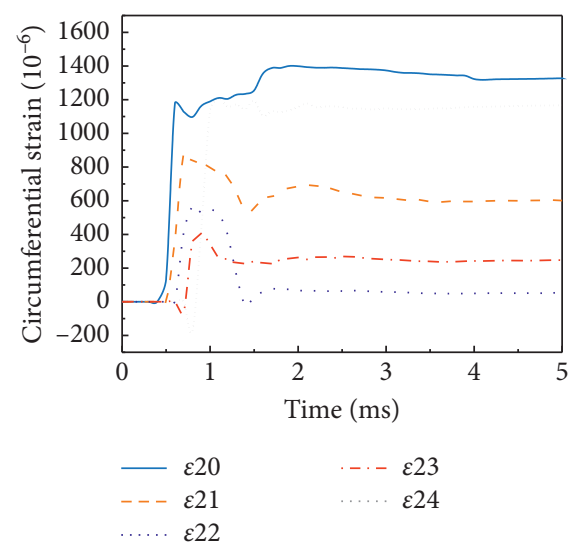

(e)

FIGURE 12: The circumferential strain-time curves of the measuring points. (a) Measuring points $\varepsilon_{1}-\varepsilon_{5}$. (b) Measuring points $\varepsilon_{6}-\varepsilon_{9}$. (c) Measuring points $\varepsilon_{10}-\varepsilon_{14}$. (d) Measuring points $\varepsilon_{15}-\varepsilon_{19}$. (e) Measuring points $\varepsilon_{20}-\varepsilon_{24}$.

measuring point $\varepsilon_{17}$ rapidly rises to the peak tensile strain, and then rapidly drops and changes into a compressive strain, while measuring point $\varepsilon_{19}$ changes from a compressive strain state to a tensile strain state. Figure 12(e) shows that the circumferential strain of the measuring point at the right floor is always tensile, while the left floor generates compressive circumferential strain first and then turns to tensile circumferential strain, and the final residual circumferential strain is tensile.

\section{Conclusions}

To evaluate the influence of multiple explosion sources on the underground cavern, based on a similarity model test, the damage evolution and circumferential strain distribution law of underground cavern in the seven cases are analyzed by using the numerical analysis method, and the following main conclusions are obtained: 
(1) In the cases of multiple explosion sources, the stress of the surrounding rock in the middle part of the two explosion sources is greater than that of the corresponding single explosion source.

(2) The damage of the underground cavern is mainly concentrated around the explosion source, the ground, and the free surface of the cavern. The damage of the surrounding rock in the cases of multiple explosion sources is not a simple cumulative superposition of the damage of the surrounding rock in the corresponding single explosion source cases. The difference lies in the middle part of the two detonation sources, where the damage degree and range of multiple detonation sources are larger.

(3) The damage of the surrounding rock at the junction of the reinforced area and nonreinforced area increases obviously, and high-strength concrete can be used to improve the performance of the surrounding rock during the construction process.

(4) The peak circumferential strain from the vault to the side arch is all tensile, and from the vault to the spandrel, it changes from tensile to compressive. The vault can easily be damaged when encountering explosions, and the support should be strengthened.

(5) When explosions occur near the sidewall, the floor will produce tensile circumferential strain, and such explosions should be avoided.

\section{Data Availability}

The data used to support the findings of this study are available from the corresponding author upon request.

\section{Conflicts of Interest}

The authors declare that there are no conflicts of interest regarding the publication of this paper.

\section{Acknowledgments}

This research was supported by the State Key Project of National Natural Science Foundation of China (Grant No. U1810203).

\section{References}

[1] H. Xie, J. Zhu, T. Zhou, K. Zhang, and C. Zhou, "Conceptualization and preliminary study of engineering disturbed rock dynamics," Geomechanics and Geophysics for Geo-Energy and Geo-Resources, vol. 6, no. 2, pp. 1-14, 2020.

[2] J. B. Zhu, Y. S. Li, S. Y. Wu, R. Zhang, and L. Ren, "Decoupled explosion in an underground opening and dynamic responses of surrounding rock masses and structures and induced ground motions: a FEM-DEM numerical study," Tunnelling and Underground Space Technology, vol. 82, pp. 442-454, 2018.

[3] C. Wu, M. Lukaszewicz, K. Schebella, and L. Antanovskii, "Experimental and numerical investigation of confined explosion in a blast chamber," Journal of Loss Prevention in the Process Industries, vol. 26, no. 4, pp. 737-750, 2013.
[4] I. C. Tolias, J. R. Stewart, A. Newton et al., "Numerical simulations of vented hydrogen deflagration in a mediumscale enclosure," Journal of Loss Prevention in the Process Industries, vol. 52, pp. 125-139, 2018.

[5] W. Xu, W. Wu, and Y. Lin, "Numerical method and simplified analytical model for predicting the blast load in a partially confined chamber," Computers \& Mathematics with Applications, vol. 76, no. 2, pp. 284-314, 2018.

[6] R. K. Singh, "Composite wall test-chamber assessment for hydrogen blast loads," Thin-Walled Structures, vol. 126, pp. 220-237, 2018.

[7] A. J. Hendron, "Engineering of rock blasting on civil projects," in Structural and Geotechnical Echanics, A Volume Honoring NM Newmark, W. J. Hall, Ed., Prentice-Hall, Hoboken, NY, USA, 1977.

[8] P. K. Singh, "Blast vibration damage to underground coal mines from adjacent open-pit blasting," International Journal of Rock Mechanics and Mining Sciences, vol. 39, no. 8, pp. 959-973, 2002.

[9] X. Xia, H. B. Li, J. C. Li, B. Liu, and C. Yu, "A case study on rock damage prediction and control method for underground tunnels subjected to adjacent excavation blasting," Tunnelling and Underground Space Technology, vol. 35, pp. 1-7, 2013.

[10] J. Xu, Y. Kang, X. Wang, G. Feng, and Z. Wang, "Dynamic characteristics and safety criterion of deep rock mine opening under blast loading," International Journal of Rock Mechanics and Mining Sciences, vol. 119, pp. 156-167, 2019.

[11] P. K. Rajmeny, U. K. Singh, and B. K. P. Sinha, "Predicting rock failure around boreholes and drives adjacent to stopes in Indian mines in high stress regions," International Journal of Rock Mechanics and Mining Sciences, vol. 39, no. 2, pp. 151164, 2002.

[12] B. L. Kutter, L. M. O’Leary, P. Y. Thompson, and R. Lather, "Gravity-scaled tests on blast-induced soil-structure interaction," Journal of Geotechnical Engineering, vol. 114, no. 4, pp. 431-447, 1988.

[13] M. C. R. Davies, "Buried structures subjected to dynamic loading," in Structures Subjected to Dynamic Loading, R. Naryanan and T. M. Roberts, Eds., pp. 271-302, Elsevier, Amsterdam, Netherland, 1991.

[14] A. De and R. Conry, "Modeling of surface blast effects on underground structures," in Proceedings of the 2011 American Society of Civil Engineers Geo-Frontiers Congress, pp. 1534-1543, Dallas, TX, USA, March 2011.

[15] A. De, A. N. Morgante, and T. F. Zimmie, "Numerical and physical modeling of geofoam barriers as protection against effects of surface blast on underground tunnels," Geotextiles and Geomembranes, vol. 44, no. 1, pp. 1-12, 2016.

[16] J. Shen, J. C. Gu, A. M. Chen, J. M. Xu, Z. Q. Ming, and X. Y. Zhang, "Development and applications of the model test apparatus on anti-explosion structures in geotechnical engineering," Chinese Journal of Underground Space and Engineering, vol. 6, pp. 1077-1080, 2007.

[17] J. C. Gu, A. M. Chen, J. M. Xu et al., "Model test study of failure patterns of anchored tunnel subjected to explosion load," Chinese Journal of Rock Mechanics and Engineering, vol. 27, no. 7, pp. 1315-1320, 2008.

[18] G. Y. Wang, J. C. Gu, A. M. Chen, J. M. Xu, and X. Y. Zhang, "Model test research on anti-explosion capacity of underground openings with end wave-decay by holes and reinforced by dense rock bolts," Chinese Journal of Rock Mechanics and Engineering, vol. 29, no. 1, pp. 51-58, 2010.

[19] J. M. Xu and J. C. Gu, "Model test study of anti-explosion capacity of anchored tunnel with local lengthening anchors in 
arch springing," Chinese Journal of Rock Mechanics and Engineering, vol. 31, no. 11, pp. 2182-2186, 2012.

[20] G. C. Xu, W. Z. Yuan, and J. C. Gu, "Explosive resistivity of anchored cavern surface rock," Chinese Journal of Rock Mechanics and Engineering, vol. 34, no. 09, pp. 1767-1776, 2015.

[21] X. Chang, G. Wang, C. Tang, and Z. Ru, "Dynamic behavior of cement-mortar cavern reinforced by bars," Engineering Failure Analysis, vol. 55, pp. 343-354, 2015.

[22] M. H. Mussa, A. A. Mutalib, R. Hamid, S. R. Naidu, N. A. M. Radzi, and M. Abedini, "Assessment of damage to an underground box tunnel by a surface explosion," Tunnelling and Underground Space Technology, vol. 66, pp. 64-76, 2017.

[23] J. Zhu, Y. li, Q. Peng, X. Deng, M. Gao, and J. Zhang, "Stress wave propagation across jointed rock mass under dynamic extension and its effect on dynamic response and supporting of underground opening," Tunnelling and Underground Space Technology, vol. 108, Article ID 103648, 2021.

[24] X. F. Deng, S. G. Chen, J. B. Zhu, Y. X. Zhou, Z. Y. Zhao, and J. Zhao, "UDEC-AUTODYN hybrid modeling of a large-scale underground explosion test," Rock Mechanics and Rock Engineering, vol. 48, no. 2, pp. 737-747, 2014.

[25] S. Kuili and V. R. Sastry, "A numerical modelling approach to assess the behaviour of underground cavern subjected to blast loads," International Journal of Mining Science and Technology, vol. 28, no. 6, pp. 975-983, 2018.

[26] X. F. Deng, J. B. Zhu, S. G. Chen, Z. Y. Zhao, Y. X. Zhou, and J. Zhao, "Numerical study on tunnel damage subject to blastinduced shock wave in jointed rock masses," Tunnelling and Underground Space Technology, vol. 43, no. 6, pp. 88-100, 2014.

[27] G. Ma, H. Hao, and Y. Zhou, "Assessment of structure damage to blasting induced ground motions," Engineering Structures, vol. 22, no. 10, pp. 1378-1389, 2000.

[28] C. Gao, Z. Zhou, Z. Li, L. Li, and S. Cheng, "Peridynamics simulation of surrounding rock damage characteristics during tunnel excavation," Tunnelling and Underground Space Technology, vol. 97, Article ID 103289, 2020 pages, 2020.

[29] Y. B. Yang, X. Y. Xie, and R. L. Wang, "Numerical simulation of dynamic response of operating metro tunnel induced by ground explosion," Journal of Rock Mechanics \& Geotechnical Engineering, vol. 2, no. 4, pp. 373-384, 2010.

[30] G. Y. Wang, J. C. Gu, A. M. Chen, J. M. Xu, and X. Y. Zhang, "Model tests on anti explosion anchoring effect of tunnels reinforced by dense bolts at arch top," Chinese Journal of Geotechnical Engineering, vol. 31, no. 3, pp. 378-383, 2009.

[31] T. J. Holmquist and G. R. Johnson, "A computational constitutive model for glass subjected to large strains, high strain rates and high pressures," Journal of Applied Mechanics, vol. 78, no. 5, Article ID 051003, 2011.

[32] L. M. Taylor, E. P. Chen, and J. S. Kuszmaul, "Microcrackinduced damage accumulation in brittle rock under dynamic loading," Computer Methods in Applied Mechanics and Engineering, vol. 55, no. 3, pp. 301-320, 1986.

[33] Y. D. Murray, A. Abu-odeh, and R. Bligh, Evaluation Of LSDYNA Concrete Material Model 159; FHWA-HRT-05-062, US Department of Transportation, Federal Highway Administration National Transportation Systems Center, Mclean, VA, USA, 2007.

[34] W. Riedel, K. Thoma, and S. Hiermaier, "Penetration of reinforced concrete by BETA-B-500 numerical analysis using a new macroscopic concrete model for hydrocodes," in Proceedings of the 9th International Symposium on the Effects of Munitions with Structures, pp. 315-322, Berlin-Strausberg, Berlin, Germany, May 1999.

[35] W. Riedel, N. Kawai, and K.-i. Kondo, "Numerical assessment for impact strength measurements in concrete materials," International Journal of Impact Engineering, vol. 36, no. 2, pp. 283-293, 2009.

[36] T. Borrvall and W. Riedel, "The RHT concrete model in LSDYNA," in Proceedings of the 8th European LS-DYNA Users Conference, pp. 23-24, Strasbourg, France, May 2011.

[37] J. O. Hallquist, LS-DYNA Keyword User's Manual, Livermore Software Technology Corporation: California, Livermore, CA, USA, 2007.

[38] R. Meyer, J. Kohler, and A. Homburg, Explosivespp. 339-341, Wiley VCH, Weinheim, Germany, 5nd edition, 2002.

[39] TM 5-855-1, Fundamental of Protective Design for Conventional Weapons, US Army Engineers Waterways Experimental Station, Vicksburg, Mississippi, USA, 1986.

[40] T. Zhou, S. L. Dong, G. F. Zhao, R. Zhang, S. Y. Wu, and J. B. Zhu, "An experimental study of fatigue behavior of granite under low-cycle repetitive compressive impacts," Rock Mechanics and Rock Engineering, vol. 51, no. 10, pp. 31573166, 2018. 